\title{
CONDICIONES SOCIOLABORALES DE LOS MÉDICOS GENERALES EN PASTO (COLOMBIA): UNA APROXIMACIÓN DESCRIPTIVA Y EXPLICATIVA*
}

Recibido: 9 de mayo de 2014 Aprobado: 18 de agosto 2015

\author{
Alba Jakeline Ruano** \\ Francisco Javier Villamarín ${ }^{* * *}$
}

\section{RESUMEN}

El objetivo del artículo es conocer las condiciones sociolaborales de los médicos generales del municipio de Pasto en el año 2012. Los datos analizados provienen de la encuesta que aplicó la Academia Nacional de Medicina, capítulo Nariño, la Secretaría Municipal de Salud de Pasto y el Observatorio Social del Departamento de Sociología de la Universidad de Nariño a una muestra de 216 médicos. La descripción de los gráficos y tablas se realiza con base en los datos y se acompaña con explicaciones extraídas de la bibliografía consultada. Esta exploración arroja evidencias de precariedad que afectan la calidad de vida material y no material de los médicos.

\section{PALABRAS CLAVE}

Médicos generales, fuerza de trabajo, características demográficas, condiciones laborales.

\section{CLASIFICACIÓN JEL}

J01; J21; J24; J44; J81; J82

\section{CONTENIDO}

Introducción; 1.Caraterísticas demográficas; 2. Características relacionadas al empleo; 3. Condiciones materiales y no materiales de vida; 4 . Satisfacción y expectativas laborales; 5 . Discusión; Bibliografía; Anexos.

* El artículo se deriva del proyecto de investigación denominado: "Condiciones sociolaborales de los médicos generales del municipio de Pasto en el año 2012", proyecto que fue ejecutado por el Grupo Multidisciplinario de Investigación Social (GRUMIS), del Departamento de Sociología de la Universidad de Nariño, el cual se encuentra clasificado en categoría C en Colciencias. La entidad que patrocinó su realización fue la Secretaría Municipal de Salud de Pasto, por encargo de la Academia Nacional de Medicina, Capítulo Nariño. Su ejecución tomó un año: de septiembre de 2011 a diciembre de 2012.

** Socióloga, Universidad de Nariño, Pasto, Colombia. Magíster en Sociología, Universidad Nacional de Colombia, Bogotá, Colombia. Estudiante del Doctorado en Estudios Sociales, Universidad Externado de Colombia, Bogotá, Colombia. Docente tiempo completo del Departamento de Sociología de la Universidad de Nariño, Pasto, Colombia. Integrante del Grupo de Investigación GRUMIS. Correo electrónico: albajakeline@gmail. com.

*** Sociólogo, Universidad de Nariño, Pasto, Colombia. Magíster en Sociología, Universidad del Valle, Cali, Colombia. Estudiante del Doctorado en Estudios Sociales, Universidad Externado de Colombia, Bogotá, Colombia. Docente tiempo completo del Departamento de Sociología de la Universidad de Nariño, Pasto, Colombia. Líder del grupo de investigación GRUMIS. Correo electrónico: paches74@udenar.edu.co. 


\section{SOCIAL AND WORKING CONDITIONS OF GENERAL DOCTORS IN PASTO (COLOMBIA): A DESCRIPTIVE AND EXPLANATORY APPROACH}

\section{ABSTRACT}

The objective of this article is to learn about the socio-occupational conditions of general physicians in the municipality of Pasto for 2012. The data has been drawn from surveys made by the National Medicine Academy, chapter Nariño, the Pasto Municipal Secretary Office of Health and the Social Observatory of Nariño University Sociology Department from a sample of 216 physicians. The graphs and tables description is based on the data and is supported with explanations that have been extracted from the consulted bibliography. The research gives clear evidence of the precariousness that affects the quality of life (material and non-material) of the physicians.

\section{KEY WORDS}

General physicians, Labor force, Demographic characteristics, Labor conditions.

\section{JEL CLASSIFICATION}

$\mathrm{J} 01 ; \mathrm{J} 21 ; \mathrm{J} 24 ; \mathrm{J} 44 ; \mathrm{J} 81$; J82

\section{CONTENT}

Introduction; 1.demographic characteristics; 2. Labor related characteristics; 3. Material and non-material conditions of life; 4 Labor satisfactions and expectations; 5. Discussion; Bibliography; Attachments.

\section{CONDIÇ̃ES SOCIAIS E DE TRABALHO DOS MÉDICOS GERAIS EM PASTO (COLÔMBIA): UMA APROXIMAÇÃO DESCRITIVA E EXPLICATIVA RESUMO}

O objetivo do artigo é conhecer as condições sócio-laborais dos médicos gerais do município de Pasto no ano de 2012. Os dados analisados provem da enquete que aplicou a Academia Nacional de Medicina, capítulo Nariño, a Secretaria Municipal de Saúde de Pasto e o Observatório Social do Departamento de Sociologia da Universidad de Nariño a uma mostra de 216 médicos. A descrição dos gráficos e tabelas se realiza com base nos dados e se acompanha com explicações extraídas da bibliografia consultada. Esta exploração produz evidências de precariedade que afetam a qualidade de vida material e não material dos médicos.

\section{PALABRAS CHAVE}

Médicos Gerais, Força de trabalho, Características demográficas, Condições laborais.

\section{CLASSIFICAÇÃO JEL}

J01; J21; J24; J44; J81; J82

\section{CONTEÚDO}

Introdução; 1.Caraterísticas demográficas; 2. Características relacionadas ao emprego;

3. Condições materiais e não materiais de vida; 4. Satisfação e expectativas laborais; 5.

Discussão; Bibliografia; Anexos. 


\section{INTRODUCCIÓN}

Según Morales, Chavarriaga y Barrero (2001), la situación que afrontan los médicos generales en los planos laboral y económico es bastante delicada, debido, entre otros, a tres factores: primero, la reforma del sistema de seguridad social en salud a través de la aprobación e implementación de la Ley 100 de 1993; segundo, la difícil situación social, económica y política por la que atraviesa el país, a la cual se suman los procesos de globalización y neoliberalismo que tornan muy competitivo y precario el mercado de trabajo, y tercero, la proliferación de facultades de Medicina que han generado un aumento de la oferta de médicos que no llegan a emplearse en su totalidad.

La implementación de la Ley 100 de 1993 ha proletarizado al médico, y ha minado su autonomía. Ahora, la vida laboral de los médicos se circunscribe a atender un elevado número de clientes o usuarios, mediante los criterios de eficiencia y celeridad. Con esto, el médico pierde su libertad en la toma de decisiones diagnósticas y terapéuticas, ya que impera el mandato burocrático. Además, manifiestan su inconformidad con los ingresos percibidos y con la precarización de sus condiciones laborales, las cuales consideran un efecto de la norma, y de su política de flexibilización laboral que, como dice Ramírez (2011, p. 2), no solo trae inestabilidad e incertidumbre "... sino que les obliga a incrementar sus jornadas, con el fin de mantener un ingreso monetario que les garantice un nivel de vida decoroso, que responda a las exigencias de sus hogares y el entorno social".

Asimismo, Guzmán (1999, p. 50) considera que la reforma ha limitado la práctica médica, y ha minado la calidad de la atención y cuidado del paciente. En su opinión: "Los horarios se han recortado, los médicos se han visto obligados a aumentar el volumen de trabajo, pero han recortado el tiempo dedicado al paciente y se ha limitado el número de exámenes de laboratorio, radiológicos y el costo de las fórmulas médicas".

Otro de los aspectos que ha incidido de forma negativa en la realidad de los médicos es la difícil situación social, económica y política que afronta el país, que también ha repercutido en el ámbito de la salud. En los últimos años, por las medidas de modernización económica que se han impulsado en los contextos global y nacional, muchas entidades públicas de salud se privatizaron o se cerraron.

Uno de los conflictos que trajo consigo este cambio fue el deterioro del tipo de vinculación laboral. De acuerdo con Poveda (2013), se ha incrementado el número de profesionales de la salud que son contratados a través de formas enrarecidas, como las cooperativas de trabajo, las empresas intermediarias y las órdenes de servicios prestados, que no les brindan ningún tipo de seguridad y, además, afectan 
su cotización a los sistemas de seguridad social en salud y pensión. En su opinión, estamos cerca de presenciar a los primeros médicos generales pensionados con un salario mínimo.

Otros estudios, como los de Morales, Chavarriaga y Barrero (2001), muestran que los médicos generales tienen que dedicarse a actividades diferentes a las de la disciplina, o complementarias a la misma, como las tareas administrativas, el comercio de artículos de consumo por catálogo, el transporte público, entre otros, para poder cubrir sus gastos mensuales y vivir de forma digna. Del mismo modo, para los que desarrollan las actividades propias de su oficio, las horas de trabajo y las tareas que deben ejecutar han aumentado, sin que eso implique un aumento en su remuneración mensual. Su preocupación principal es que las empresas de salud ya no los quieren vincular con contrataciones permanentes sino temporales.

Otra causa que ha generado el detrimento de la práctica de la profesión ha sido la proliferación de facultades de Medicina en el país, que, Según Fernández y otros (2011), pasaron de 7 facultades en los años 60 del siglo pasado, a 58 en la primera década del presente milenio. Esto quiere decir que cada año, en promedio, egresan aproximadamente 3.000 nuevos profesionales, principalmente de universidades privadas, en esta área de la salud. Esta situación está produciendo una sobreoferta de profesionales que el mercado de trabajo no puede absorber de forma satisfactoria.

De igual manera, este crecimiento descontrolado de las facultades y carreras de Medicina ha afectado la calidad de la formación médica. Algunos estudiosos del problema como Fernández y otros $(2011$, p. 110) sostienen que la apertura descontrolada de programas de Medicina que promulgó la Ley 30 de 1992, "... desmejoró desde los procesos de selección y admisión de estudiantes, pasando por sus centros de práctica asistencial, y su potencial para ser fuente investigación, hasta los procesos para formar galenos de alta capacidad científica y humana".

Según su opinión, el Estado ha buscado resolver este problema otorgando reconocimientos, como la acreditación de alta calidad y los registros calificados, sistemas que buscan asegurar la calidad de la educación, pero ha pasado por alto otros criterios complementarios, como la producción científica, la capacitación docente, y la proyección a la comunidad, que son esenciales para alcanzar este objetivo.

Este panorama problemático de la realidad social y laboral de los médicos generales en Colombia, y de modo particular en el municipio de Pasto, formula los siguientes interrogantes: ¿Cuáles son las condiciones sociolaborales de los médicos generales del municipio de Pasto en el año 2012? ¿Cómo son sus condiciones materiales y no materiales de vida? ¿Cuál es su grado de satisfacción o insatisfacción con su realidad laboral, salarial, económica y social? 
Condiciones sociolaborales de los médicos generales en Pasto (Colombia): una aproximación descriptiva y explicativa

Este artículo se propone conocer las condiciones sociolaborales de los médicos generales del municipio de Pasto en el año 2012, para interpretarlas desde diferentes perspectivas teóricas y empíricas multidisciplinarias. Para responder de modo parcial a las preguntas antes formuladas, se acude a los resultados arrojados por la Encuesta de caracterización sociolaboral aplicada a esta población por la Academia Nacional de Medicina, Capítulo Nariño (ver anexo C), la Secretaría de Salud Municipal de Pasto y el Observatorio Social del Departamento de Sociología de la Universidad de Nariño. Sin embargo, hay que advertir que las estadísticas sociales producidas por esta investigación son superficiales, y los interrogantes e hipótesis que plantea deben ser profundizados y solucionados en otro momento, con otro tipo de estrategias de investigación como entrevistas, observaciones y análisis documental de tipo histórico y de actualidad; por el momento los resultados cuantitativos obtenidos permiten levantar un panorama general de la situación social, laboral y económica de este gremio en el caso particular de una ciudad intermedia.

La encuestal se aplicó en los meses de mayo, junio y julio de 2012 a los médicos generales titulados que laboraban en las instituciones prestadoras de salud del municipio, y en otras organizaciones de tipo académico y administrativo que contemplan dentro de su personal a esta clase de profesionales. Como no se encontró un marco muestral de esta población, se construyó para este caso un listado de instituciones de salud y de otras organizaciones donde labora esta población, listado que permitió la identificación de un universo de 511 sujetos (anexo A). A partir de este universo, se extrajo un tamaño de muestra de 216 sujetos, con un $95 \%$ de confiabilidad y un 5,1 \% de error. Este tamaño de muestra fue distribuido de forma proporcional y aleatoria de acuerdo con el volumen de las instituciones y organizaciones identificadas (revisar anexo B).

Este artículo está dividido en seis partes incluyendo esta introducción: en la primera parte se presenta el análisis y discusión de las características demográficas de la población observada. La segunda parte aborda el tema de la realidad del empleo de este gremio. La tercera y cuarta parte están destinadas al estudio de las condiciones materiales y no materiales de vida de los médicos, así como al conocimiento de sus expectativas y actitudes frente a sus condiciones sociolaborales actuales. Por último, a partir de los hallazgos encontrados, se presentan unas conclusiones que buscan entablar discusiones con otras investigaciones similares.

\footnotetext{
1 La encuesta fue el resultado de un proceso de operación de los conceptos de investigación y de las teorías consultadas, así como de la revisión de otros instrumentos de medición nacional, como la Encuesta de Médicos Generales Colombianos, de la cual se tomaron respetuosamente algunas preguntas para asegurar la comparación de los resultados.
} 


\section{CARACTERÍSTICAS DEMOGRÁFICAS}

En lo referente a las características demográficas de los médicos generales que laboran en las 35 instituciones públicas y privadas ubicadas en el municipio de Pasto, se encontró que de una muestra de 216 médicos que participaron en el estudio, el 48,61 $\%$ corresponde a hombres y el $51,39 \%$ restante a mujeres. En cuanto a la edad se evidenció que el mayor porcentaje (32,87 \%) se ubicó en el rango de 25 a los 29 años, seguido por un 23,61 \% que oscila entre los 30 y los 34 años, una menor proporción $(13,89 \%)$ tiene 50 años y más, otro 11,57 \% tiene entre 35 y 39 años. Los grupos de edad de 45 a 49 años, de 40 a 44 años y de 20 a 24 años presentaron porcentajes inferiores al $10 \%$. Algunos cálculos más cuantitativos indican que la edad promedio de los médicos es de 36 años, la edad que más se repite es 28 años, la puntuación mediana es 32 años, la edad máxima es 60 años y la mínima es de 23 años. Según esta información, la población de médicos generales que labora en Pasto es joven.

Estos datos son cercanos a los alcanzados por otras investigaciones similares desarrolladas en el país, y en algunas de sus regiones como el departamento de Caldas. Por ejemplo, con respecto a la edad, en el país, según estudios realizados por Gualtero y otros (2007), el promedio de edad de los galenos es de 37,5 años, y según Ramírez (2011) en el departamento cafetero el promedio es de 38,2 años. La dispersión de los promedios observados en el país, en Caldas y en Pasto es de 0,92 , lo cual nos indica la proximidad de los datos, y la normalidad de los mismos.

Sin embargo, los estudios consultados revelan diferencias con este estudio en lo referente a la composición de la población por sexo. Los estudios nacionales de Lasso (2009) y Ramírez (2011) indican que en las muestras analizadas la participación de los hombres ha sido superior a las de las mujeres. Este mismo comportamiento se observa en estudios realizados con médicos psiquiatras, como la investigación liderada por Gómez-Restrepo y otros (2003).

No obstante, el hecho de que las mujeres comiencen a ser mayoría en la profesión médica, como lo describe este estudio, no es nada raro, pues para algunos investigadores internacionales, como Heimerdinger (2010, p. 437), es algo normal "... debido a que el número de graduados [en la actualidad] es mayor en ellas". La prevalencia de mujeres en el oficio médico en esta parte del país es un hecho que causa curiosidad, y que es necesario profundizarlo en una investigación complementaria.

Frente al estado civil, se observó que el 52 \% son solteros, seguidos por un 37,50 \% de casados, un 6,02 \% que vive en unión libre, un 3,24 \% que son separados o divorciados y mínimo porcentaje de viudos. Además de ser una población joven, el mayor porcentaje de ellos y ellas, para el año 2012, no ha definido aún su situación conyugal, y/o no ha tomado la decisión de formar una familia. 
Condiciones sociolaborales de los médicos generales en Pasto (Colombia): una aproximación descriptiva y explicativa

El panorama que revelan los datos en lo concerniente al estado civil se explica por dos factores que pueden estar interrelacionados: primero, por su juventud, y, segundo, por la urgencia de cumplir algunos proyectos profesionales y económicos de tipo personal renuncian o postergan las uniones conyugales y la fecundidad; frente a esto, lo más seguro es que, como población cualificada y en pleno proceso de ascenso social y económico, experimenten lo que en sociología de la población se conoce como segunda transición demográfica, fenómeno caracterizado por algunos expertos entre estos Sánchez (2008, p.43) como: "(...) el fuerte declive de la nupcialidad, que se manifiesta en que la edad para casarse ha subido y en el aumento de la proporción de solteros (...) [así como también en] una creciente diversidad de los tipos y las formas de la familia"2.

Del mismo modo, la encuesta reveló que $62,04 \%$ de los consultados nacieron en Pasto, el 25,46 \% viene de otros municipios de Nariño, 11,11 \% son originarios de otros municipios de Colombia y 0,93 \% llegaron de otros países. En definitiva, se puede observar que el mayor porcentaje de los médicos consultados son originarios de la ciudad de Pasto.

En cuanto al estrato socioeconómico, se puedo observar que el $44,91 \%$ vive en una residencia ubicada en el estrato 3; el 34,3\% se ubica en una vivienda de estrato 4, el 11,11\% habita en una vivienda de estrato 5, el 9,7 \% restante vive en una vivienda de estrato 2 .

La distribución de la población según el tipo de institución universitaria de egreso muestra que el $53 \%$ de los médicos terminaron sus estudios en una institución nacional de carácter privado, el 36 \% en una institución pública nacional y un $9 \%$ en una universidad pública extranjera.

La distribución de los médicos por estrato socioeconómico y la institución universitaria de egreso es muy similar a la de sus pares nacionales. Con respecto al primer aspecto, las investigaciones consultadas en el país evidencian que el 55,7 $\%$ de los médicos reside en viviendas ubicadas en los estratos tres y cuatro. Sin embargo, algunas cifras históricas referenciadas por estudios como los de la Gualtero y otros (2007) denuncian un desmejoramiento de la calidad de vida de este grupo, y un descenso en su estrato socioeconómico, ya que en el año 2001 este grupo se ubicaba en los estratos 4 y 5 .

Este estudio reporta una realidad similar a la registrada por esta encuesta, en lo concerniente a la universidad de egreso. Según Gualtero y otros (2007) en el país,

2 Este proceso modernizador -la segunda transición demográfica- es diferencial en los grupos o segmentos que configuran la sociedad, y depende, en gran medida, del grado de bienestar y desarrollo socioeconómico de estas fracciones. No es un fenómeno homogéneo. 
los médicos obtienen su título profesional de universidades privadas en un 48,9\%, frente al $46,1 \%$ de los galenos que se titula en universidades públicas y el 3,8 \% que se profesionaliza en universidad extranjeras.

\section{CARACTERÍSTICAS RELACIONADAS CON EL EMPLEO}

La investigación de las características relacionadas con el empleo de los médicos generales comienza con la exploración del tiempo acumulado de experiencia laboral. Frente a este ítem, una significativa proporción (35,2\%) dice que su experiencia no supera los cinco años; un 25,9\% ha trabajado entre 5 y 9 años; y otro 10,7 \% acumula en el oficio entre 10 y 14 años de su vida. Este estudio describe que los médicos que reportan una amplia trayectoria en su profesión solo representan un $24 \%$ del total; de ellos el 8,3\% tiene más de 25 años de experiencia; el 8,4 \%, entre 20 y 24 años, y el 6,9\%, entre 15 y 19 años. Por último, solo el 4,2\% de los médicos tiene menos de un año de experiencia laboral.

En este apartado también se da cuenta de los lugares donde se han desempeñado como profesionales de la Medicina. Se observa que su oficio lo han realizado en Pasto (94\%) y en otros municipios del departamento de Nariño (48,6 \%); otras proporciones más modestas han desarrollado sus laborales en otros municipios de Colombia (19,4\%) y del extranjero (2,3\%) (Porcentaje este último representado por los médicos que recibieron su formación en una institución universitaria internacional).

Otro de los indicadores extraídos para caracterizar el empleo de los médicos generales es el número de empresas donde laboran en la actualidad. La observación describe que un $46,3 \%$ trabaja en dos instituciones, seguido de un $44,9 \%$ que solo trabaja en una institución. Los porcentajes de médicos que laboran en tres o más entidades es muy bajo, de acuerdo con los datos estudiados $(5.6 \%$ y $09 \%$, respectivamente). Por último, un 2,3\% no aporta información frente a esta característica.

Este estado de cosas deja ver que el personal médico que labora en la ciudad debe, en la mayoría de los casos, multiemplearse para obtener los ingresos necesarios para cubrir sus gastos personales y familiares. Sin embargo, de acuerdo con los resultados arrojados por las investigaciones consultadas, la sobrecarga de trabajo puede traer efectos negativos tanto en la prestación del servicio médico, como también en la salud física y psicológica de los propios galenos. En lo referente a la prestación del servicio médico, los horarios extensos, las múltiples actividades del oficio y los trabajos en diferentes empresas pueden repercutir de modo negativo en su atención y vigilancia, hechos que pueden ocasionar lo que se conoce en medicina como el error humano o el infortunio, patología que según Bocanegra (2012) puede alterar tanto el diagnóstico como el tratamiento, por ejemplo, en el caso de las actividades asistenciales. 
Condiciones sociolaborales de los médicos generales en Pasto (Colombia): una aproximación descriptiva y explicativa

En la salud de los médicos, las jornadas extenuantes de trabajo, además de alterar las horas de sueño y los niveles de atención y concentración, pueden propiciar un desgaste físico y emocional. De forma paralela a las jornadas extendidas de trabajo, estos profesionales laboran en ambientes adversos llenos de presiones, agresiones, intimidaciones, riesgos legales y amenazas de todo tipo, que según algunas investigaciones especializadas pueden desembocar en el síndrome del hombre quemado o la enfermedad de Burnout ${ }^{3}$.

Por otro lado, la encuesta preguntó sobre el medio más utilizado por los médicos para conseguir trabajo. Dentro de las múltiples opciones elegidas para emplearse figuran, en su orden, los contactos o redes sociales de familiares amigos y conocidos (las famosas "palancas") (53,2 \%), el envío de hojas de vida a varias empresas (43,1 \%), las convocatorias y concursos abiertos, en particular los que ofrece el sector público (23,1 \%), otros medios (2,8 \%), (como el mérito propio y la fundación de empresas), los avisos clasificados y las oficinas de empleo con un 2,3\%, respectivamente.

Estos resultados concuerdan con la realidad que afrontan otras profesiones y actividades económicas en la región y en el país, donde las "palancas" son el método más efectivo para conseguir empleo. Esta fenómeno se explica, según algunos expertos nacionales, porque en un mercado laboral donde impera la informalidad económica y la escasez de oportunidades, la clave para conseguir trabajo consiste en tener buenos contactos (El Tiempo, 2012).

De igual manera, un indicador que brinda elementos para conocer con mayor detalle la realidad del empleo de este grupo es el tipo de empresa que los contrata. La muestra indica que la mayor parte de los encuestados trabaja en una entidad privada (56,5\%), otro porcentaje labora en entidades del Estado (39,3\%), y una pequeña proporción se encuentra vinculada a empresas de tipo solidario (4,2 \%).

De forma complementaria con el tipo de empresa al que se encuentran vinculados, la encuesta indagó sobre el tipo de contratación. La información obtenida deja ver que de los 216 médicos encuestados, un 54,87 \% se encuentran vinculados a sus organización por medio de un contrato de servicios y otras formas de vinculación, mientras que un poco menos de la mitad (45,13\%) son trabajadores de planta.

3 Una enfermedad moderna caracterizada, según Herranz y otros (2006, p. 746), por una respuesta orgánica y emocional al estrés crónico que surge cuando el trabajador experimenta un elevado cansancio emocional, despersonalización y una baja realización en su trabajo. Esta enfermedad no es exclusiva de esta población, sino que se puede decir que en la actualidad es general a todas las ocupaciones que configuran la moderna división del trabajo social de un mundo cada vez más instrumental y mercantilizado, donde, como dice Marx (1980, p. 105): "(...) el trabajo es externo al trabajador, es decir, no pertenece a su ser; [en] su trabajo, el trabajador no se afirma, sino que se niega; no se siente feliz, sino desgraciado; no desarrolla una libre energía física y espiritual, sino que mortifica su cuerpo y arruina su espíritu (...) Su trabajo no es, así, voluntario, sino forzado, trabajo forzado..." 
Otro elemento a tener en cuenta es el relacionado con las actividades que desarrollan en su empleo principal ${ }^{4}$. Del $100 \%$ de los consultados, el 86,6\% desarrolla actividades clínicas en su empleo principal; otras actividades que figuran en los datos analizados, y que completan este reporte, son, en su orden: las actividades administrativas, con un 5,1 \%; las actividades de promoción y prevención, con un $4,18 \%$; las actividades de docencia, con un 2,3\%, y otras actividades (como la investigación y la asistencia), con un $19 \%$. Así las cosas, en su mayoría, los médicos consultados realizan actividades clínicas en el empleo que ellos consideran como el más importante.

Una pregunta que complementa los datos analizados hasta el momento es: ¿̇cada cuánto tiempo le es renovado su contrato de trabajo?, cuya respuesta presenta el siguiente panorama: un $38,9 \%$ de los médicos consultados tienen un contrato a término indefinido; a un 29,6\% le renuevan su contrato cada año; a un 15,7 \%, cada seis meses, y a un $0,5 \%$, cada mes. Dentro de los datos observados hay que destacar un 5,6\% de médicos que manifiesta que el tiempo de duración de su vinculación laboral no concuerda con las opciones ofrecidas en la encuesta.

Estos resultados se asemejan a los reportados por la investigación realizada por Gualtero y otros (2007). Las coincidencias se observan, primero, en que los mayores porcentajes de médicos trabajan en una entidad privada; según esta indagación, la proporción en el país es del 48,5\%; esta tendencia se presenta en las estadísticas nacionales desde el año 2005, período en que la actividad médica más efectuada fue la asistencial, seguida por las funciones administrativas y de docencia, según Ramírez (2011); y, segundo, en que en la mayoría de los casos los contratos de estos profesionales son a término indefinido.

Por otro lado, los ingresos mensuales totales ${ }^{5}$ de los médicos generales, es decir, el conjunto de los ingresos que estos perciben tanto en su empleo principal como en otras actividades complementarias, revelan el siguiente panorama: de los 216 médicos consultados 142 (65,7\%) devengan un ingreso total cada mes que oscila entre los $\$ 2.000 .001$ y los $\$ 4.000 .000 ; 44(20,4 \%)$ ganan entre $\$ 4.000 .001$ y $\$ 6.000 .000 ; 24$ (11,1\%), entre \$1.000.001 y \$2.000.000; 5 (2,3\%), más de \$6.000.001, y 1 (0,5\%), menos de $\$ 400.000$ al mes. El estudio también reveló que, en general, los ingresos son superiores a sus egresos, pues estos últimos fluctúan entre $\$ 1.000 .000$ y $\$ 2.000 .000$ al mes. Esto se explica porque parte del dinero que devengan, lo ahorran, o lo invierten en proyectos socioeconómicos personales.

4 Por empleo principal se entiende en este estudio, el trabajo al que los médicos generales le dedican más tiempo, y del cual reciben un salario mayor y relativamente estable. A esta definición se llegó después de relacionar el tipo de vinculación laboral con el ingreso mensual.

5 Es la suma de los ingresos percibidos en el empleo principal más los ingresos provenientes de actividades complementarias. 
Condiciones sociolaborales de los médicos generales en Pasto (Colombia): una aproximación descriptiva y explicativa

Los ingresos de los médicos de la ciudad son similares a los de los galenos de otras partes del país. Sin embargo, según Poveda (2013), su monto es sinónimo de precarización laboral y disminución de su calidad de vida, ya que 20 años atrás los ingresos de este grupo eran del orden de los 20 salarios mínimos legales. Hoy, según el sentir de los propios médicos generales colombianos, y después de verse obligados a rebuscar en varios sitios de trabajo, sometiéndose a jornadas que ponen en riesgo su salud física y emocional, como se expresó más arriba, apenas alcanzan los 4 o 5 salarios mínimos. Así las cosas, se puede conjeturar que en el futuro su estabilidad económica y salarial no tiende a mejorar, y de mejorarse, con seguridad, será en contra de ellos mismos, y del ambiente social y familiar que los rodea.

Otro de los indicadores que da cuenta de las características y de la calidad del empleo son las capacitaciones, congresos y cursos continuados en los cuales participan los médicos. De los 216 encuestados en este estudio, el 53,7 \% participa de estos espacios de conocimiento de forma ocasional, por lo menos una vez al año; otro 31 \% sostiene que asiste con alguna regularidad (por lo menos cada dos meses); otro $13 \%$ hace parte de estas actividades de manera muy frecuente (una vez al mes), y el 2,3 \% restante no participa nunca en estos cursos.

En lo referente al número de capacitaciones y cursos de formación que reciben de su empresa, el estudio muestra que un significativo 63,4 \% participa en menos de cuatro cursos de esta naturaleza al año. Los que reciben entre 10 y 14 capacitaciones representan el $13,4 \%$ y los que asisten entre 5 y 9 veces suman un $12,5 \%$. Los que participan en más de 15 capacitaciones al año representan el 10,7 \% restante. En síntesis, la encuesta revela un bajo número de capacitaciones para un grupo de profesionales de quienes se espera un alto nivel de actualización y conocimiento, sobre todo, cuando bajo su responsabilidad está un bien tan preciado, como es la vida.

En sintonía con la pregunta anterior, también se les formuló a los médicos este interrogante: ¿̇btiene apoyo económico por parte de su empleador para asistir a congresos y capacitaciones de actualización? Los resultados muestran que la mayoría de estos profesionales no recibe apoyo económico de sus empleadores para participar en estos eventos (72,2\%), respuesta que concuerda con los datos expuestos. Otro 18,1 \% dice que recibe de manera ocasional esta clase de estímulos; otro 8,8 $\%$ dice que su empresa siempre patrocina su participación en estas actividades, y un escaso $0,9 \%$ no responde a la pregunta.

Sin embargo, el apoyo para que estos profesionales participen en estos espacios de actualización y formación no solo se midió en términos monetarios, sino también en la disponibilidad de tiempo que les ofrecen sus empresas. Según los resultados arrojados por la encuesta, un poco menos de la mitad de los médicos consultados 
$(48,1 \%)$ sostiene que estas organizaciones no les brindan tiempo para participar en estos cursos; un 29,6 \% manifiesta que esta clase de ayudas se las brindan de manera ocasional, y un 22,2 \% responde que sus empleadores siempre les brindan este apoyo.

Aunque los estudios sobre las condiciones sociolaborales de los médicos en Colombia no tengan en cuenta la frecuencia con que estos asisten a capacitaciones durante el año, ni tampoco los estímulos en tiempo y en dinero que sus empleadores les brindan para que participen en estos espacios, en trabajos como los de Gualtero y otros (2007) se puede evidenciar que el $60 \%$ de los médicos consultados manifiesta no tener acceso a estos cursos, ya que sus organizaciones no promueven este tipo de actividades.

Por otro lado, el estudio buscó conocer si los consultados tienen derecho a vacaciones remuneradas una vez al año en su empleo principal. Un 53,7 \% de los encuestados goza de este beneficio, mientras que un 44,9\% manifiesta no tener derecho a este reconocimiento legal. Por último, un 1,4\% se abstiene de emitir alguna respuesta. Según Gualtero y otros (2007) el porcentaje de médicos que gozan de vacaciones en la ciudad está por debajo de la proporción nacional que se encuentra en el 75,4 \%; además, una pequeña fracción de ellos (13\%) recibe incentivos para financiar sus vacaciones

\section{CONDICIONES MATERIALES Y NO MATERIALES DE VIDA}

Además de conocer la situación laboral de los médicos, esta investigación permitió un acercamiento tanto a las condiciones materiales como no materiales de vida de esta población. Las condiciones de vida tienen estrecha relación con los bienes y servicios materiales, los cuales se constituyen en medios para alcanzar un proyecto de vida, y generar condiciones de bienestar social y satisfacción de necesidades que, en principio, son de primer orden como el abrigo, el hambre y el entendimiento. Estas condiciones se asocian con las formas de producción y de consumo.

En la época moderna el sujeto busca la satisfacción de las necesidades básicas, pero también la satisfacción de las necesidades derivadas de las dinámicas del mercado y del consumo, y más que del consumo como relación social, del consumismo que caracteriza estas sociedades. Para Bauman (2007, p. 47) el consumismo debe comprenderse como:

[...] un tipo de acuerdo social que resulta de la reconversión de los deseos, ganas o anhelos humanos, (si se quiere neutrales respecto del sistema) en la principal fuerza de impulso y de operaciones de la sociedad, una fuerza que coordina la reproducción sistémica, la integración social, la estratificación social y la formación del individuo humano. 
Condiciones sociolaborales de los médicos generales en Pasto (Colombia): una aproximación descriptiva y explicativa

En consonancia con lo planteado por Bauman (2007), en la sociedad moderna las condiciones materiales de vida se encuentran relacionadas con el tipo de trabajo que se desempeñe, y en primer lugar con las dinámicas del consumismo, el aumento de la intensidad y el volumen de los deseos, de donde se desprende la propiedad de bienes tanto de uso personal como de uso familiar. En este sentido, se describen tanto los servicios básicos como los bienes con los cuales cuenta la población de médicos generales.

En cuanto al acceso que esta población tiene a los servicios básicos, se encontró que cuenta con cobertura total de los servicios de acueducto, energía eléctrica, alcantarillado y aseo. Otros servicios como televisión por suscripción e Internet llegan a un poco más del $90 \%$ de los hogares de esta población. Frente a la afiliación al régimen de salud, se pudo apreciar que el $99 \%$ de los consultados está afiliado al régimen contributivo, y el 1 \% restante está cobijado por un plan de medicina prepagada y por el régimen subsidiado.

En lo referente a la afiliación a pensiones y riesgos profesionales, se observó que el $62 \%$ de los encuestados está afiliado al sistema de pensiones de manera compartida con el empleador y por cuenta del vínculo laboral; otro 36,1 \% se encuentra afiliado de modo individual pues asume el $100 \%$ de esta obligación; otro 0,9 \% no tiene afiliación; y otro 0,9 \% restante no sabe o no responde. Además, la investigación mostró que un poco más del 97 \% de los médicos generales empleados se encuentra afiliado a riesgos profesionales, mientras el otro 2,3\% restante manifestó no estar afiliado a este sistema de seguridad social.

Otro de los indicadores para aproximarse a las condiciones materiales de vida de los médicos generales es la propiedad de bienes de uso personal y familiar. Los artículos que más posee esta población son en su orden: teléfono celular (96,7 \%), televisor (93,9\%), DVD/VHS, (87 \%), equipo de sonido (82,9\%), nevera o refrigerador $(82,4 \%)$, biblioteca $(79,2 \%)$, máquina lavadora de ropa $(78,7 \%)$, horno microondas (75,9\%), carro particular (68,5\%), computador portátil (57,4\%), calentador eléctrico de agua (46,3\%), calentador de agua a gas (41,6\%), bicicleta (39,5\%), casa (35,7 \%), consola de juegos (30,6 \%), apartamento (25,5\%), acciones empresariales (17,6 \%), finca de recreo $(11,7 \%)$, blue ray $(11,1 \%)$ y motocicleta $(9,7 \%)$. Cada uno de estos artículos y servicios son bienes y satisfactores que hacen parte de la supervivencia del ser humano y del goce de una calidad de vida que incluye gustos, deseos y la satisfacción de otras necesidades generadas y potenciadas bajo las dinámicas del consumo de las sociedades contemporáneas.

Las condiciones no materiales de vida, por su parte, se relacionan más con las dinámicas relacionales, organizacionales, gustos, aprovechamiento del tiempo libre, 
ocio, situaciones asociadas a la calidad de vida que no se encuentran relacionados con bienes y servicios. En este orden de ideas, Sen (1985) plantea que no todas las actividades de las personas se dirigen a la maximización del bienestar material. Las personas están en continua interacción y cambian de manera constante sus preferencias, cumplen sus obligaciones morales y culturales impuestas por las creencias $y$, por ende, pueden tener razones suficientes para conseguir objetivos diferentes al modelo de bienestar que le impone la sociedad. En este sentido, el bienestar y la calidad de vida no estarían determinados por las utilidades económicas sino por las capacidades, es decir, las características de las que les permiten a las personas funcionar y acceder a una vida más plena.

El tiempo que comparten y las actividades que desarrollan con la familia, la frecuencia de participación en reuniones sociales, la actividades que realizan en el tiempo libre, los deportes que practican, los viajes que realizan en vacaciones, los libros que leen al año, entre otros aspectos, son indicadores que permiten realizar una aproximación a la cotidianidad y a la calidad de vida no material que caracteriza a estos profesionales.

Frente al primer aspecto, el 46,76\% de los médicos afirma que comparte de dos a cuatro horas diarias con sus familias, el 37,5 \% dice compartir más de cuatro horas diarias; el 12,04 \% comparte menos de dos horas diarias, y el 1,85\% manifiesta no compartir tiempo con la familia. Durante el tiempo que los médicos comparten con sus respectivas familias desarrollan diferentes actividades como ir a comer y pasear (79,17 \% en cada opción), seguidas por actividades como dialogar (75,46 \%), ver televisión (68,52\%), ir al cine $(33,80 \%$ y la actividad que menos realizan con sus familias es hacer deporte $(31,02 \%)$.

En lo referente a las actividades que desarrollan en su tiempo libre, los médicos prefieren ir al gimnasio $(65,28 \%)$, hacer deporte $(30,09 \%)$, ir al cine $(26,85 \%)$, bailar $(25,93 \%)$ y salir con los amigos (18,52\%). Pero en otro extremo se encuentran las actividades que nunca realizan en sus ratos de ocio, y entre estas el primer puesto lo ocupa la lectura $(53,24 \%)^{6}$, ver televisión $(39,81 \%)$, escuchar música $(37,5 \%)$, orar (35,19\%), descansar (34,72\%) y salir con la familia (31,48\%). De todo esto, se destaca el bajo interés de los médicos por la lectura; entre aquellos médicos que manifestaron leer algún tipo de literatura se encontró un promedio de 3 libros al año. La realidad de los médicos en este aspecto no se aleja de la que se vive en el contexto colombiano. Al respecto, el MEN (2012) estima que:

6 Dato que torna más compleja y problemática la realidad de los médicos generales de la ciudad con respecto a sus bajas posibilidades de capacitación y actualización, como se mencionó más arriba. 
Condiciones sociolaborales de los médicos generales en Pasto (Colombia): una aproximación descriptiva y explicativa

Colombia registra índices de hábitos de lectura precarios, hecho que se refleja en niveles de consumo de libros y de utilización de las bibliotecas muy inferiores a los de países con altos e incluso similares niveles de desarrollo... Se estima que de un total de 13.023.964 habitantes que conforman la población en edad de trabajar ubicada en las principales áreas urbanas, más de 30 \% no lee.

Este panorama es preocupante, ya que uno de los profesionales más comprometidos con la lectura en esta, la denominada sociedad del conocimiento y la información, debería ser el médico en cualquiera de sus especialidades. Este vacío supone serias implicaciones en su nivel de conocimientos, la actualización de los mismos y la calidad de su servicio. Este indicador, sumado al bajo número de capacitaciones en las que participan, es un factor de riesgo para la salud de los pacientes. En consecuencia, como dice Álvarez (2012), cada vez es más notorio que "[el médico] que funcionaba como el eje de la atención de los enfermos desapareció, para ser reemplazado por una especie de técnico (...) con formación irregular y conocimientos apenas rudimentarios (...)".

Por último, otro aspecto que se describe en esta investigación está relacionado con la frecuencia con que viajan estos profesionales de la salud en plan de vacaciones, tanto dentro como fuera del país. Al respecto el 38,89\% de los médicos viaja una vez por año a itinerarios nacionales en plan de descanso; el 28,70 \% manifiesta que cuando hay oportunidad; el 15,28 \% dos veces por año y el 10,65\% manifiesta no viajar por falta de recursos y de tiempo. El mayor porcentaje de médicos $(39,35$ \%) nunca ha viajado en plan de vacaciones fuera del país; el 33,33 \% manifiesta haber viajado cuando hay oportunidad; el 19,91 \% manifiesta ir de vacaciones al extranjero una vez por año, y el 5,09\% ha viajado cada dos años con el objeto de visitar otros países.

\section{SATISFACCIÓN Y EXPECTATIVAS LABORALES}

Para poder avanzar en el conocimiento de la situación sociolaboral de los médicos generales, la encuesta permitió conocer su grado de satisfacción con su realidad actual, las expectativas que tienen frente a su vida laboral y su vida cotidiana, y el conocimiento que poseen frente al actual régimen de salud.

Sen (1985) y Max Neff (2006) manifiestan que el grado de satisfacción, la percepción y los sentimientos de las personas frente a sus formas de vida, su trabajo y sus relaciones sociales pueden estar determinados por aspectos no materiales de vida, y su análisis permite conocer las capacidades, oportunidades y habilidades que la persona posee de manera natural y espontánea. Asimismo, Villagómez, Hernández y Villareal (2003, p. 399) en investigaciones sobre la satisfacción laboral en médicos de la ciudad de México mencionan que "(...) la sensación de satisfacción puede favorecer el mejor desempeño del profesional, y (...) las organizaciones médicas deben también servir a los 
intereses de los prestadores de servicios". En este sentido, el poder ahondar en el grado de satisfacción y las expectativas de este grupo brinda elementos para avanzar en el análisis de su calidad de vida.

Investigaciones de carácter empírico han mencionado que la satisfacción laboral está relacionada con la percepción placentera y subjetiva de las experiencias laborales, o la respuesta afectiva de la persona a su trabajo y a las condiciones en que lo realiza; de la misma manera se menciona que la satisfacción se asocia a factores intrínsecos (personales) o extrínsecos (ambiente de trabajo y recursos disponibles). En este sentido, se afirma que la calidad de vida profesional se basa en el equilibrio entre la carga de trabajo percibida y la satisfacción por actividades profesionales específicas ${ }^{7}$.

En relación con el grado de satisfacción e insatisfacción con algunas situaciones que configuran la realidad social y laboral de los médicos, el presente estudio encontró que frente a las condiciones de vida: el mayor porcentaje de médicos se encuentra satisfecho (63,0 \%); el 22,2 \% manifiesta sentirse muy satisfecho; el 10,6 $\%$ no se sienten ni satisfecho ni insatisfecho, y solo el 3,2 \% manifiesta sentirse insatisfecho. En cuanto a las actividades que realiza en el tiempo libre, el 58,3 \% dice sentirse satisfecho; el 13,4\%, muy satisfecho; el 13,4 \%, ni satisfecho ni insatisfecho, y el 14,8 \% se siente insatisfecho. En relación con los ingresos obtenidos en su ejercicio profesional, el 42,1 \% manifiesta sentirse satisfecho; el 8,3\%, muy satisfecho; el 25,5\% manifiesta sentirse insatisfecho, y un 5,1 \% muy insatisfecho. En cuanto a la calidad del sistema de salud vigente, se observa que el mayor porcentaje de población manifiesta sentirse insatisfecho (43,1\%), y muy insatisfecho $(28,2 \%)$; solo el 7,9\% se muestra satisfecho con el sistema de salud vigente. Frente a las condiciones laborales actuales los médicos generales manifiestan sentirse satisfechos.

Algunos médicos especialistas consultados afirman que estos resultados son sinónimo de conformismo, resignación y tal vez una falsa satisfacción, asociada más a la capacidad para adquirir bienes personales y familiares, que a la realización plena de las expectativas y los proyectos personales y profesionales. Frente a este tema, se ha mencionado que la satisfacción del profesional es considerada como un factor determinante en la calidad del servicio y en la atención que los médicos puedan prestar a sus pacientes. Al respecto Sánchez, Álvarez y Lorenzo (2003, p. 291) sostienen que "... no es posible conseguir que una persona realice un trabajo, con calidad y eficiencia si no se encuentra satisfecha durante el desempeño y con los resultados del mismo...".

Sin embargo, las explicaciones a este comportamiento son apenas una exploración, o una primera aproximación; valdría la pena profundizar estos aspectos en

7 Acercamientos conceptuales citados por Valderrama y Dávalos-Díaz (2009). 
otros estudios donde se investiguen, con mayor profundidad, los factores asociados a la satisfacción e insatisfacción de estos profesionales en el marco de sus actuales condiciones sociolaborales.

Por otro lado, las expectativas de los médicos generales se asocian con los proyectos personales inmediatos, y con la forma como visualizan su vida en los próximos cinco años. Frente al primer aspecto, el mayor porcentaje de consultados (68,5 \%) les gustaría estudiar; en una proporción menor (40,3\%), continuar con su trabajo en la ciudad de Pasto, seguidos por un porcentaje importante $(15,3 \%)$ que manifiesta que le gustaría trabajar en otro país, y una baja proporción (3,2 \%) tiene la intención de retirarse; dentro de este último grupo se ubican las personas que se encuentran en edad de jubilación.

En referencia al segundo aspecto, el 24,54 \% tiene como expectativa continuar con su trabajo; un 12,5\% espera montar un negocio diferente a la salud; un 7,87 \% buscaría un empleo en otra ciudad para mejorar su situación económica, y el mayor porcentaje de población tiene otro tipo de expectativa; la que más se repite es continuar con sus estudios, y en menor porcentaje, ser feliz o establecer una relación de pareja.

Como se observa, al tratarse de una población relativamente joven (36 años de edad en promedio), una de sus expectativas más importantes es continuar con sus estudios. Al respecto se les preguntó sobre qué área de la Medicina les gustaría profundizar: el mayor porcentaje está interesado en estudiar pediatría (16,4 \%), seguido de quienes desean estudiar Medicina Interna (14,87 \%), Anestesiología (7,94 \%), Ginecología (5,82\%), cirugía (5,29\%), ortopedia (4,76\%) y dermatología (4,76\%).

El estudio también quiso averiguar sí los médicos que hicieron parte de la muestra contaban con horas libres para trabajar, a lo que el 51,85\% respondió de manera afirmativa y el 48,15 \% restante manifestó no tener horas disponibles para este propósito. Entre quienes respondieron de manera afirmativa a esta pregunta, se encontró que el promedio de horas disponibles en la semana es de 24 horas; el tiempo mínimo es de dos horas a la semana, y el máximo 40 horas a semanales. En este mismo orden de ideas, el $50 \%$ de los que respondieron de manera afirmativa tienen menos de 20 horas disponibles a la semana y el 50 \% restante tiene más de 20 horas disponibles.

Por último, los objetivos planteados por la encuesta no buscaban profundizar el nivel o tipo de conocimiento que los médicos generales tienen frente al sistema nacional de seguridad social en salud, sino establecer un acercamiento a la opinión que tienen sobre la Ley 100 de 1993, y a la calificación que le asignan a la calidad 
del servicio médico en Colombia. Los resultados arrojados dejan ver que los encuestados tienen un conocimiento medio de la ley general de seguridad social, y en este mismo sentido, la valoración que le dan a la calidad del servicio de médico en Colombia bajo este sistema es regular (60,65\%), en menores porcentajes lo califican como malo (20,37 \%) y muy malo (11,11 \%), un minimo porcentaje lo califica bueno $(6,94 \%)$ y muy bueno $(0,93 \%)$.

En general, manifiestan sentirse afectados por las disposiones de esta ley frente al ejercicio médico, en aspectos relacionados con la autonomía médica, los tipos de contratación y los bajos ingresos mensuales. Al respecto en la propuesta de Reforma de la Ley 100 planteada por el médico Alberto Mendoza (2009, p. 4) presidente del Colegio Nacional de Médicos Generales de Colombia, se expresa:

Este modelo y sistema han convertido al médico y a todos los profesionales en operarios de un mercado creado con ánimo de lucro impactando negativamente las más mínimas reivindicaciones laborales del trabajador de la salud sufriendo en carne propia la perversidad de este modelo.

Toca ajustar lo tendiente al recurso humano para la salud en cuanto al tratamiento que económicamente deben justamente percibir como producto de su actividad laboral. Es menester tener en cuenta que si quien presta el servicio lo realiza en condiciones infraestructurales antitéticas, recibe un mal trato en educación médica continuada y salarialmente, el resultado de la atención va a tener deficiencias.

Asimismo, los médicos manifiestan que frente a la Ley 100 hay muchas cosas para analizar y debatir, entre ellas: los vacíos en cuanto al programa de pensiones, las directrices del Plan Obligatorio de Salud, la ley anti-trámites, el sistema de información, y el problema financiero y administrativo. En síntesis, opinan que esta ley favorece más a los usuarios del sistema de salud y al sector de médicos especialistas, que a los propios médicos generales.

\section{DISCUSIÓN}

De esta experiencia se pueden extraer muchas reflexiones debido a la riqueza de los datos analizados, y sus diversas posibilidades de desagregación. Sin embargo, por tratarse de una aproximación a un fenómeno que no se ha investigado en la ciudad ni en gran parte del país, una primera lectura de las condiciones sociolaborales de los médicos generales revela un panorama problemático, en el que se destacan evidencias de precariedad laboral e interpretaciones distorsionadas de la realidad, que generan en los galenos confusiones y contradicciones, que son un rasgo distintivo de las nuevas formas que asume el capitalismo, en especial en sus versiones más flexibles. 
Condiciones sociolaborales de los médicos generales en Pasto (Colombia): una aproximación descriptiva y explicativa

Las nuevas formas del capitalismo flexible, que no son ajenas a las empresas de salud de la ciudad, hacen que sus empleos y la forma de contratación no les ofrezcan mayores seguridades ni estabilidad laboral, lo que repercute en la disminución de sus ingresos mensuales, situación que los lleva a acudir al rebusque, y emplearse en varios trabajos para satisfacer sus necesidades materiales más fundamentales.

Las tendencias que describen las investigaciones realizadas en el país, y la comparación de las mismas con los resultados de este trabajo muestran que su situación desmejora, y de seguir la difícil situación económica del país y de la región, complementada con el escaso valor que el mercado le da a la capacitación profesional, debido a que su interés se centran en incrementar la rentabilidad de las empresas de salud, dicha complejidad no presenta un buen pronóstico. Para evitar escenarios futuros desfavorables, sería importante que el Estado y las entidades que regulan y vigilan la práctica médica en el país, así como la misma sociedad sobre quien recae la acción de estos profesionales, tomen cartas en el asunto y formulen proyectos de políticas públicas que sean tenidos en cuenta en las próximas reformas laborales del sector salud en el país y en la región.

Otro hecho que genera preocupación según Senett (1998) es que los conflictos sociales y laborales que afrontan los médicos afectan su forma de percibir e interpretar su realidad, lo que da lugar a nuevas formas de alienación. Presentan percepciones confusas de su situación laboral y salarial, y en algunas ocasiones su trabajo los vuelve tan superficiales que no entienden lo que pasa a su alrededor.

Esta es una patología social y económica que ya se denuncia en las sociedades más desarrolladas, y en estas latitudes ya comienza a expresarse en el gremio médico en la ambigüedad con que describen su realidad en la encuesta. Por ejemplo, llama la atención que se sienten satisfechos con su trabajo, con sus ingresos mensuales, con las actividades que desarrollan en su trabajo y con su calidad de vida, pero al mismo tiempo, y de forma paradójica, denuncian no estar de acuerdo con el sistema de salud vigente y califican de modo regular la efectividad de la Ley 100 de 1993, ley que determina la calidad de su ocupación, de sus salarios, de su continuidad laboral y del rol que ejercen en la sociedad. No tienen conciencia, según la lógica de Senett (1998), de que aquello que les genera malestar y temor es lo que permite su satisfacción profesional.

Otra patología de este estilo, que por cierto es muy preocupante, es su constante denuncia por el escaso número de capacitaciones especializadas que reciben al año, y los pocos estímulos monetarios y de tiempo para participar en congresos y seminarios de investigación médica que les permitan estar actualizados. Sin embargo, 
no acuden a la lectura de textos especializados ni de materiales de investigación para desarrollar su conocimiento médico, pues según la encuesta, una de las actividades que menos realizan es la lectura de material bibliográfico de cualquier clase. Es decir, son conscientes de la precariedad de su trabajo, pero no emprenden acciones individuales o de grupo que los lleven a superar esta clase de conflictos.

Otro aspecto que es importante destacar es el marcado individualismo que caracteriza a este grupo, que se aprecia de modo especial por el tipo de consumo de bienes y servicios materiales que realizan. Debido, quizá, a que se trata de un población joven, que reside aún en la casa de sus padres, que en su mayoría no ha asumido compromisos de tipo conyugal ni familiar, y que planean proyectos académicos y personales que les permitan ascender en la escala social y económica, adquieren bienes y servicios materiales, como teléfonos celulares, computadores, tabletas, entre otros, que reafirman su espíritu individualista ${ }^{8}$. Este comportamiento comprueba que este gremio está experimentando un período de cambio en el que las obligaciones colectivas son reemplazadas por la libertad individual y la vida privada, cambio que, acudiendo a la lógica de Bauman (2002), se puede categorizar como el paso de lo "sólido" a lo "líquido".

Es importante aclarar que los conflictos sociales y laborales que afronta la población de médicos generales, que han sido identificados en este trabajo, no solo son explicados porque son una particularidad de este gremio y de su subjetividad. Los datos arrojados por la encuesta dejan ver que las estructuras socioeconómicas del presente también influyen sobre el bienestar y la calidad de vida de los galenos, y también según Berguer y Lukmann (1996) permiten conocer más de cerca sus percepciones y sus crisis de sentido frente a sus expectativas, sus proyectos, y sus actitudes con respeto a algunas situaciones personales, laborales y normativas. La fusión de la dimensión estructural y subjetiva en el análisis y la interpretación de esta clase de fenómenos, como dice Mills (1961, p. 25-26), es fundamental "Ipara dejar] todo lo mejor [en] los estudios sobre el hombre y la sociedad".

Para finalizar es importante mencionar que las interpretaciones, explicaciones y puntos de vista expuestos en este artículo tienen un carácter hipotético y discutible. Más que certezas, este ejercicio empírico arroja interrogantes y puntos sobre los cuales se puede dinamizar la polémica en torno a cómo mejorar las condiciones sociolaborales de esta población.

8 La encuesta revela también que poseen artículos domésticos y que tienen accesos a todos los servicios públicos domiciliarios, pero es posible que dichos artículos pertenezcan a las viviendas de sus progenitores, y que compartan con ellos el pago de estos servicios. Esta es una hipótesis que hay que se debe comprobar en futuros ejercicios de investigación de corte cualitativo que profundicen este tema. 
Condiciones sociolaborales de los médicos generales en Pasto (Colombia): una aproximación descriptiva y explicativa

En este sentido, esta investigación identifica situaciones problemáticas de la realidad social, laboral y económica de estos profesionales de la ciudad de Pasto en el año 2012, que se espera sean la base de las futuras reformas de la salud, especialmente en el campo de su vinculación al mercado de trabajo, como el mejoramiento de sus condiciones laborales, mejoramiento que no únicamente implica incrementar sus salarios y sus prestaciones, sino también estimular su participación en cursos de actualización en el campo médico y su proyección como servicio social de primera necesidad. Cambios como este deben estar acompañados de una mayor autonomía para el ejercicio de su oficio y de una mayor cantidad de tiempo para la recreación y el desarrollo personal, familiar y social.

\section{BIBLIOGRAFÍA}

Álvarez, Gustavo (2012). 12. El médico general, una especie extinta. [En línea] Diario Portafolio. Bogotá. [Consultado 10 de octubre de 2012].

Bauman, Zygmund (2002). Modernidad líquida. México: Fondo de Cultura Económica, 231p.

Bauman, Zygmunt (2007). Vida de consumo. Buenos Aires: Fondo de Cultura Económica, 208p.

Berguer, Peter y Lukmann, Thomas (1996). Modernidad, pluralismo y crisis de sentido. ¿Qué necesidades humanas básicas orientación deben ser satisfechas? En Revista de Estudios Públicos. N. ${ }^{\circ}$ 63, invierno, p. 1-54.

Bocanegra, Juan (2012). Sobrecarga laboral en los profesionales de la salud y su relación con la seguridad del paciente. En Panorama, Vol. 18, N. ${ }^{\circ}$ 1, 2012, pp. 6-13.

Centro de Investigaciones Sociológicas de España-CIS (2002).V Encuesta Nacional de Condiciones de Trabajo en España. [En línea] CIS, Madrid, 2002, 27p. [Consultado 30 de enero de 2013]

DANE (2012). Gran Encuesta Integrada de Hogares. [En línea] Archivo Nacional Estadístico, Bogotá, 31p. [Consultado 28 de enero de 2013]

El Tiempo (2012). Palanca, detrás del 69.3\% del empleo. [En línea] Del Tiempo [Consultado el 9 de julio de 2012]

Fernández, Daniel; Mancipe, Liliana; Fernández, Diana; Reyes, Elsa; Díaz, María y Martín, Juan (2011). Análisis de la oferta de pregrados en medicina en Colombia durante los últimos 30 años (1980-2010). En: Revista Colombiana de Reumatología. Vol. 18, N. 2, junio, p. 109 - 120

Gómez-Restrepo, Carlos; Bohórquez, Adriana; Felizzola, Carlos; Gil, Fabián; Díaz-Granados, Nancy y Heinz, Elizabeth (2003). Perfil del médico psiquiatra colombiano. En: Revista Colombiana de Psiquiatría, Vol. 23, N. ${ }^{\circ}$, octubre-diciembre, p. 325-340. 
Gualtero, Martha; Betancourt, Jairo; Pardo, Hilario; Orejuela, Alexandra y González Lyda (2007). Autonomía médica y su relación con la prestación de los servicios de salud. Bogotá: Defensoría del Pueblo, 79p.

Guzmán, Fernando (1999). Futuro del gremio médico ¿Qué hacer? En: Revista Colombiana de Reumatología. Vol. 5, ‥ 2, mayo de 1999, p. 108-113.

Heimerdinger, Clemente (2010). Situación socioeconómica de los médicos en Venezuela. En: Colección Razetti, Vol. 9, 2010, p. 425-440.

Herranz, José; Reig-Ferrer, Abillo y Cabera-García, Julio (2006). La prevalencia del estrés laboral asistencial entre los profesores universitarios. En: Revista Análisis y Modificaciones de la Conducta, Vol. 3, N. ${ }^{\circ}$ 146, 2006, p. 743-766

Lasso, María (2009). Desempeño laboral de los médicos egresados de los diplomados de medicina alternativa de la Universidad Libre-Cali. En: Revista Entramado, Vol. 5, N. 1, enero-junio, 2009, p. 108-115.

Marx, Karl (1980). Manuscritos económicos y filosóficos de 1844. [En línea] Archivo de Chile y CEME, 38p. [Consultado 4 de febrero de 2011]

Max Neff, Manfred (2006). Desarrollo a escala humana. Barcelona: Nordan - Comunidad, 148p.

Mendoza, Alberto (2009). Propuesta de reforma a la Ley 100 de 1993. Bogotá, Colegio de Médicos Generales de Colombia, 34p.

Mills, Wright (1961). La imaginación sociológica. México: FCE, 316p.

Morales, Luis Gonzalo, Chavarriaga, Ilse y Barrero, Javier (2001). Condiciones laborales y de vida de los médicos en Colombia. 1996-1998. Bogotá: Fundación Corona y Fundación Presencia, 74p.

Ministerio de Educación Nacional-MEN (2012). Plan Nacional de Lectura y Bibliotecas. [En línea] Colombia aprende Bogotá, p. 34. [Consultado 22 de enero de 2013]

Poveda, Juan (2013). La realidad en gráficos de los médicos generales. Resultados de encuesta realizada en 2013. [En línea] Médicos generales colombianos, Bogotá, 2013. [Consultado 15 de septiembre de 2015]

Ramírez, Jorge (2011). Impacto de la reforma de la salud en Colombia en la calidad de vida de los médicos de Caldas. Manizales: Universidad Nacional de Colombia, 163p.

Observatorio Social (2013). Condiciones sociolaborales de los médicos generales del municipio de Pasto. [En línea] Observatorio Social. Universidad de Nariño, Pasto, 70p.

Sánchez, Jesús (2008). El crecimiento de la población mundial. Implicaciones socioeconómicas, ecológicas y éticas. Madrid: Tirant lo Blanch, 653p. 
Condiciones sociolaborales de los médicos generales en Pasto (Colombia): una aproximación descriptiva y explicativa

Sánchez, R., Álvarez, R. y Lorenzo, S. (2003). Calidad de vida profesional de los trabajadores de atención primaria del área 10 de Madrid. En: Medifam, Vol. 13, N. 4, abril, p. 291-296.

Sen, Amartya (1985). Commodities and Capabilities, Ámsterdam, North-Holland, 130p.

Senett, Richard (1998). La corrosión del carácter. Las consecuencias personales del nuevo capitalismo. Barcelona: Anagrama, 188p.

Valderrama, José y Daválos-Díaz, Guillermina (2009). Factores de satisfacción laboral en médicos familiares del IMSS. En: Revista de Investigación Clínica Vol. 61, N.ํ2, marzo-abril de 2009, p. 119-126.

Villagómez, María; Hernández, Alejandra y Villareal, Enrique (2003). Satisfacción laboral de los médicos a seis años de distancia 2003. En: Revista de Médica del Instituto Mexicano de Seguridad Social, Vol. 41, N. ${ }^{\circ}$, 2003, p. 399-405. 


\section{ANEXOS \\ Anexo A. Marco muestral de la encuesta}

\begin{tabular}{|c|c|c|}
\hline N. ${ }^{\circ}$ & Institución & $\begin{array}{c}\text { Número de Médicos } \\
\text { Generales }\end{array}$ \\
\hline 1 & Pasto salud ESS & 104 \\
\hline 2 & Saludcoop EPS & 50 \\
\hline 3 & Proinsalud & 49 \\
\hline 4 & Saludcoop Clínica Los Andes & 41 \\
\hline 5 & Hospital Infantil & 35 \\
\hline 6 & Fundación Hospital San Pedro & 28 \\
\hline 7 & Universidad San Martín & 26 \\
\hline 8 & Clínica Nuestra Sra. de Fátima & 25 \\
\hline 9 & Hospital Civil & 19 \\
\hline 10 & Nueva EPS & 15 \\
\hline 11 & Hospital Universitario Departamental & 14 \\
\hline 12 & Medicoop EPS & 12 \\
\hline 13 & Universidad Cooperativa Facultad de Medicina & 11 \\
\hline 14 & Centro médico Valle de Atriz & 9 \\
\hline 15 & Área Sanidad Policía de Nariño & 9 \\
\hline 16 & Emssanar IPS & 8 \\
\hline 17 & Facultad de Medicina Udenar & 6 \\
\hline 18 & Fondo Udenar & 5 \\
\hline 19 & Cruz Roja & 5 \\
\hline 20 & Asmet Salud EPS & 5 \\
\hline 21 & Hospital Perpetuo Socorro & 4 \\
\hline 22 & Hospital San Rafael & 4 \\
\hline 23 & Sociedad Clínica Palermo & 4 \\
\hline 24 & Unidad de salud estudiantil Udenar & 4 \\
\hline 25 & MEDFAM & 4 \\
\hline 26 & Liga contra el Cáncer & 2 \\
\hline 27 & Profamilia & 2 \\
\hline 28 & INPEC & 1 \\
\hline 29 & Instituto Champagnat & 1 \\
\hline 30 & Salud Vida & 1 \\
\hline 31 & Universidad Mariana & 1 \\
\hline 32 & Prueba Pasto & 1 \\
\hline 33 & Amparo de Ancianos San José & 1 \\
\hline 34 & Colegio Bethlemitas & 1 \\
\hline 35 & IU CESMAG & 1 \\
\hline 36 & Consultorio Privado Alicia Janeth Vásquez & 3 \\
\hline \multicolumn{2}{|r|}{ TOTAL MÉDICOS } & 511 \\
\hline
\end{tabular}

Fuente: Observatorio Social (2013) 
Condiciones sociolaborales de los médicos generales en Pasto (Colombia): una aproximación descriptiva y explicativa

\section{Anexo B. Distribución proporcional del tamaño de muestra por instituciones seleccionadas}

\begin{tabular}{|c|c|c|c|}
\hline Código & Institución & Médicos & $\%$ \\
\hline 1 & Pasto salud ESS & 52 & $24,1 \%$ \\
\hline 2 & Corporación IPS & 22 & $10,2 \%$ \\
\hline 3 & Proinsalud & 15 & $6,9 \%$ \\
\hline 4 & Saludcoop Clínica Los Andes & 10 & $4,6 \%$ \\
\hline 5 & Hospital Infantil & 17 & $7,9 \%$ \\
\hline 6 & Fundación Hospital San Pedro & 11 & $5,1 \%$ \\
\hline 7 & Universidad San Martín & 9 & $4,2 \%$ \\
\hline 8 & Clínica Nuestra Sra. Fátima & 16 & $7,4 \%$ \\
\hline 9 & Hospital Civil & 9 & $4,2 \%$ \\
\hline 10 & Hospital Universitario Departamental & 7 & $3,2 \%$ \\
\hline 11 & Medicoop EPS & 6 & $2,8 \%$ \\
\hline 12 & Universidad Cooperativa-Facultad de Medicina & 4 & $1,9 \%$ \\
\hline 13 & Centro médico Valle de Atriz & 2 & $0,9 \%$ \\
\hline 14 & Área Sanidad Policía de Nariño & 6 & $2,8 \%$ \\
\hline 15 & Emssanar IPS & 2 & $0,9 \%$ \\
\hline 16 & Facultad de Medicina Udenar & 2 & $0,9 \%$ \\
\hline 17 & Fondo Udenar & 2 & $0,9 \%$ \\
\hline 18 & Cruz Roja & 4 & $1,9 \%$ \\
\hline 19 & Asmet Salud EPS & 2 & $0,9 \%$ \\
\hline 20 & $\begin{array}{l}\text { Hospital Perpetuo Socorro - Hospital San Rafael - Clínica } \\
\text { Palermo }\end{array}$ & 6 & $2,8 \%$ \\
\hline 21 & $\begin{array}{l}\text { Unidad Estudiantil Udenar-Instituto Champagnat-Universidad } \\
\text { Mariana-Colegio Bethlemitas -IU CESMAG-Consultorio } \\
\text { Privado Alicia Janeth }\end{array}$ & 3 & $1,4 \%$ \\
\hline 22 & $\begin{array}{l}\text { MEDFAM - Liga contra el Cáncer - Profamilia - INPEC - Salud } \\
\text { Vida - Prueba Pasto - Amparo de ancianos San José }\end{array}$ & 9 & $4,2 \%$ \\
\hline \multicolumn{2}{|r|}{ TOTAL } & 216 & $100 \%$ \\
\hline
\end{tabular}

Fuente: Observatorio Social (2013) 


\section{Anexo C. Encuesta de caracterización sociolaboral}

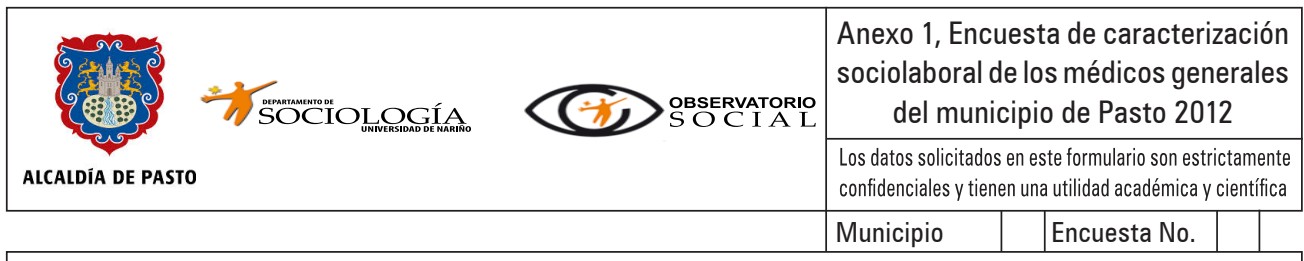

Objetivo: Caracterizar las condiciones sociolaborales de los médicos generales en el municipio de Pasto en el año 2012.

\section{INFORMACIÓN GENERAL}

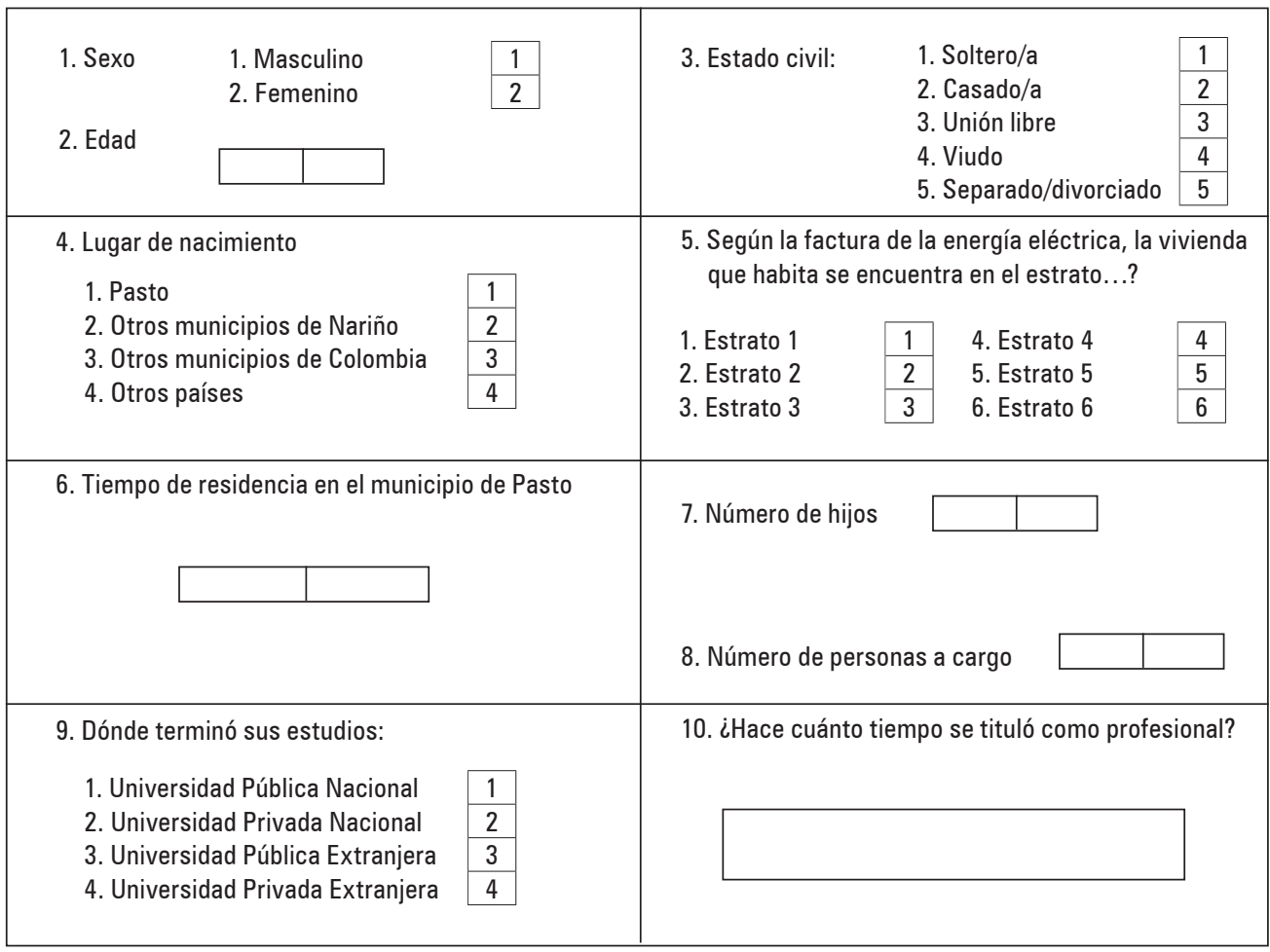

11. Tiempo de experiencia laboral
12. Municipios o ciudades donde ha laborado como médico general:
1. Pasto
2. Otros municipios de Nariño
3. Otros municipios de Colombia
4. Otros municipios del extranjero 


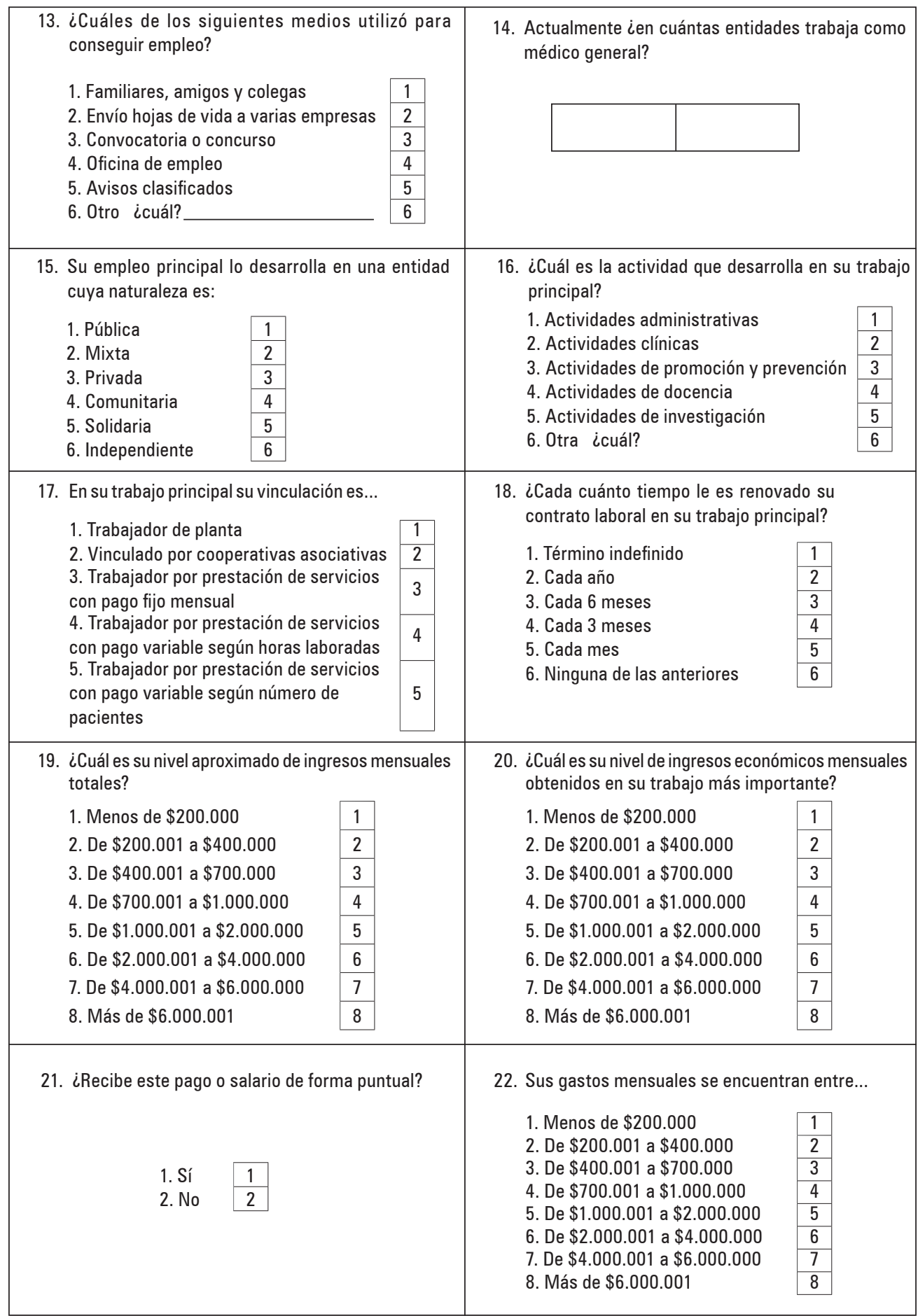


23. En Colombia la jornada laboral para empleados públicos y privados, según la ley, es de 48 horas semanales. ¿En su lugar de trabajo está sometido a jornadas que superan lo legalmente establecido?
1. Sí
2. No
3. $\mathrm{Ns} / \mathrm{Nr}$

\begin{tabular}{|l|}
\hline 1 \\
\hline 2 \\
\hline 3 \\
\hline
\end{tabular}

25. ¿Cómo califica su relación lablral y personal con su jefe inmediato?
1. Excelente
2. Buena
3. Regular
4. Mala
5. Deficiente

\begin{tabular}{|l|}
\hline 5 \\
\hline 4 \\
\hline 3 \\
\hline 2 \\
\hline 1 \\
\hline
\end{tabular}

27. ¿Cómo califica su relación profesional con sus pacientes?
1. Excelente
2. Buena
3. Regular
4. Mala
5. Deficiente

\begin{tabular}{|l|}
\hline 5 \\
\hline 4 \\
\hline 3 \\
\hline 2 \\
\hline 1 \\
\hline
\end{tabular}

29. ¿Cuánto tiempo emplea en atende a un paciente?
1. 15 minutos
2. 20 minutos
3. Más de 20 minutos

\begin{tabular}{|l|}
\hline 1 \\
\hline 2 \\
\hline 3 \\
\hline
\end{tabular}

24. ¿El lugar donde se realiza su trabajo principal cuenta con las condiciones infraestructurales, técnicas y humanas?
1. Sí

\begin{tabular}{|l|}
\hline 1 \\
\hline 2 \\
\hline
\end{tabular}
2. No

26. ¿Ha sido víctima de agresiones físicas o verbales por parte de sus superiores?
1. Sí
2. No

\begin{tabular}{|l|}
\hline 1 \\
\hline 2 \\
\hline 3 \\
\hline
\end{tabular}
3. $\mathrm{Ns} / \mathrm{Nr}$

28. ¿Ha sido víctima de agresiones físicas o verbales por parte de sus pacientes 0 sus familiares?
1. Sí
2. No

\begin{tabular}{|l|}
\hline 1 \\
\hline 2 \\
\hline
\end{tabular}

30. ¿Cuánto tiempo de receso tiene entre consulta y consulta?
1. de 1 a 3 minutos
2. De 3 a 5 minutos
3. De 5 a 10 minutos
4. De 11 a 20 minutos
5. Más de 21 minutos
6 . No tiene receso

\begin{tabular}{|l|}
\hline 1 \\
\hline 2 \\
\hline 3 \\
\hline 4 \\
\hline 5 \\
\hline 6 \\
\hline
\end{tabular}

31. ¿Recibe presiones de la empresa donde labora más tiempo para disminuir el costo de la formulación por paciente al mes?

32. ¿Recibe presiones de la empresa donde labora más tiempo para disminuir el número de órdenes diagnósticas?
1. Sí
2. No

\begin{tabular}{|l|}
\hline 1 \\
\hline 2 \\
\hline
\end{tabular}

34. ¿Recibe presiones de la empresa donde labora más tiempo para formular menos medicamentos y tratamientos por fuera del POS al mes?
\begin{tabular}{l|l|} 
1. Sí & 1 \\
2. No & 2 \\
\hline
\end{tabular}

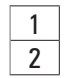

36. ¿Con qué frecuencia asiste a seminarios, congresos y capacitaciones?
1. Nunca
2. Ocasionalmente (6 meses)
3. Regularmente (2 meses)
4. Muy frecuente (mensual) 
37. ¿Obtiene apoyo económico por parte de su empleador para asistir a congresos y capacitaciones de actualización
1. Nunca
2. Ocasionalmente
3. Siempre

\begin{tabular}{|l|}
\hline 1 \\
\hline 2 \\
\hline 3 \\
\hline
\end{tabular}

38. ¿Obtiene apoyo en tiempo por parte de su sempleador para asistir a congresos y capacitaciones de actualización?
1. Nunca
2. Ocasionalmente
3. Siempre

\begin{tabular}{|l|}
\hline 1 \\
\hline 2 \\
\hline 3 \\
\hline
\end{tabular}

39. ¿En su trabajo principal, goza usted, actualmente, del derecho a tener vacaciones?

\begin{tabular}{l|l|} 
1. Sí & 1 \\
2. No & 2 \\
\hline
\end{tabular}

\section{CONDICIONES OBJETIVAS O MATERIALES DE VIDA}

40. ¿Cuál de los siguientes bienes posee?

1. Carro particular icuántos?

2. Casa ¿cuántas?

3. Apartamento ¿cuántos?

4. Finca de recreo ¿cuántas?

5. Televisor ¿cuántos?

6. DVD(VHS

7. Máquina lavadora de ropa

8. Nevera o refrigerador

9. Calentador eléctrico de agua

10. Calentador de agua a gas

\begin{tabular}{|c|c|}
\hline Sí & No \\
\hline 1 & 2 \\
\hline 1 & 2 \\
\hline 1 & 2 \\
\hline 1 & 2 \\
\hline 1 & 2 \\
\hline 1 & 2 \\
\hline 1 & 2 \\
\hline 1 & 2 \\
\hline 1 & 2 \\
\hline 1 & 2 \\
\hline
\end{tabular}

11. Horno microondas

12. Equipo de sonido

13. Computador portátil icuántos?

14. Computador de mesa icuántos?

15. Bicicleta

16. Motocicleta

17. Acciones empresariales

18. Biblioteca

19. Blue-ray

20. Teléfono móvil ¿cuántos?

21. X-Box

\begin{tabular}{|c|c|}
\hline Sí & No \\
\hline 1 & 2 \\
\hline 1 & 2 \\
\hline 1 & 2 \\
\hline 1 & 2 \\
\hline 1 & 2 \\
\hline 1 & 2 \\
\hline 1 & 2 \\
\hline 1 & 2 \\
\hline 1 & 2 \\
\hline 1 & 2 \\
\hline 1 & 2 \\
\hline
\end{tabular}

41. La vivienda que habita cuenta con los servicios
1. Alcantarillado
2. Energía eléctrica
3. Acueducto
4. Red interna de gas natural
5. Pipeta de gas

\begin{tabular}{|c|c|}
\hline Sí & No \\
\hline 1 & 2 \\
\hline 1 & 2 \\
\hline 1 & 2 \\
\hline 1 & 2 \\
\hline 1 & 2 \\
\hline 1 & 2 \\
\hline 1 & 2 \\
\hline 1 & 2 \\
\hline 1 & 2 \\
\hline 1 & 2 \\
\hline
\end{tabular}
7. Televisión por suscripción (cable o antena)
8. Internet
9. Aseo
10. Todos los anteriores

42. ¿A cuál de los siguientes regímenes de seguridad social en salud se encuentra afiliado?
1. Contributivo (EPS)
2. Subsidiado (ARS)
3. Régimen especial (Fuerzas Armadas, Ecopetrol, universidades públicas y privadas)
4. Medicina prepagada y no está afiliado/a
5. No está afiliado/a

44. ¿Cuenta con afiliación a riesgos profesionales (ARP)?

43. ¿Cuenta en este momento con afiliación a pensiones?

1. De manera compartida con el empleador $y$ por cuenta del vínculo laboral en planta

2. De manera individual asumo el $100 \%$ de

dicha obligación

3. No tengo afiliación a pensiones
1. Sí
2. No

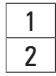

\section{CONDICIONES NO MATERIALES DE VIDA}

45. ¿En promedio, cuántas horas comparte con su familia al día?

1. Menos de dos horas

2. De 2 a 4 horas diarias

3. Más de 4 horas diarias

4. No comparte tiempo con la familia

5. Otro tiempo

¿Cuál?

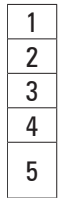


46. ¿Cuáles son las actividades que más desarrolla cuando está con su familia?
1. Ver televisión
2. Ir a cine
4. Hacer deporte
3. Pasear

\begin{tabular}{|l|}
\hline 1 \\
\hline 2 \\
\hline 3 \\
\hline
\end{tabular}
5. Dialogar
6. Comer
7. Otro
¿cuál?

47. ¿Con qué frecuencia participa de reuniones sociales con parientes y amigos?
1. Semanalmente
2. Dos veces al mes
3. Una vez al mes
4. Cada dos meses
5. Rara vez
6. Nunca

\begin{tabular}{|l|}
\hline 1 \\
\hline 2 \\
\hline 3 \\
\hline 4 \\
\hline 5 \\
\hline 6 \\
\hline
\end{tabular}

48. ¿Pertenece a alguna de las siguientes organizaciones?

1. Organizaciones de médicos

2. Cooperativas de ahorro y vivienda

3. Asociaciones profesionales

4. Otras

¿Cuáles

49. ¿Con qué frecuencia realiza las siguientes actividades en su tiempo libre?

\begin{tabular}{|c|l|c|c|c|}
\hline No. & \multicolumn{1}{|c|}{ Frecuencia } & Siempre & $\begin{array}{c}\text { Algunas } \\
\text { veces }\end{array}$ & Nunca \\
\hline 1 & Escuchar música & 3 & 2 & 1 \\
\hline 2 & Ver televisión & 3 & 2 & 1 \\
\hline 3 & Leer & 3 & 2 & 1 \\
\hline 4 & Salir con la familia & 3 & 2 & 1 \\
\hline 5 & Salir con amigos & 3 & 2 & 1 \\
\hline 6 & Ir a cine & 3 & 2 & 1 \\
\hline
\end{tabular}

\begin{tabular}{|c|l|c|c|c|}
\hline No. & \multicolumn{1}{|c|}{ Frecuencia } & Siempre & $\begin{array}{c}\text { Algunas } \\
\text { veces }\end{array}$ & Nunca \\
\hline 1 & Bailar & 3 & 2 & 1 \\
\hline 2 & Ir al gimnasio & 3 & 2 & 1 \\
\hline 3 & Orar & 3 & 2 & 1 \\
\hline 4 & Descansar (dormir) & 3 & 2 & 1 \\
\hline 5 & Practicar deporte & 3 & 2 & 1 \\
\hline
\end{tabular}

50. ¿Qué deportes practica?

\begin{tabular}{|l|l|}
\hline 1. Fútbol & 1 \\
\hline 2. Basquetbol & 2 \\
\hline 3. Tenis & 3 \\
\hline 4. Natación & 4 \\
\hline 5. Ciclismo & 5 \\
\hline 6. Otros & 6 \\
\hline \multicolumn{2}{|c|}{ ¿Cuáles) } \\
\hline 7. Ninguno & 7 \\
\hline
\end{tabular}

52. Desde que ejerce su profesión de médico icada cuánto viaja dentro del pais en plan de vacaciones?

\begin{tabular}{|l|l|}
\hline 1. Dos veces por año & 1 \\
\hline 2. Una vez por año & 2 \\
\hline 3. Cada dos años & 3 \\
\hline 4. Cuando hay oportunidad & 4 \\
\hline 5. Nunca & 5 \\
\hline
\end{tabular}

51. ¿Cuántos libros de literatura lee al año?

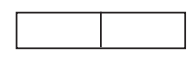

53. Desde que ejerce su profesión de médico ¿cada cuánto viaja fuera del país en plan de vacaciones?

\begin{tabular}{|l|l|}
\hline 1. Dos veces por año & 1 \\
\hline 2. Una vez por año & 2 \\
\hline 3. Cada dos años & 3 \\
\hline 4. Cuando hay oportunidad & 4 \\
\hline 5. Nunca & 5 \\
\hline
\end{tabular}


54. ¿Cuál es su creencia religiosa?

\begin{tabular}{|l|l|}
\hline 1. Católico & 1 \\
\hline 2. Cristiano/evangélico & 2 \\
\hline 3. Testigo de Jehová & 3 \\
\hline 4. Agnóstico/a & 4 \\
\hline 5. No tiene religión & 5 \\
\hline Otra & 6 \\
\hline ¿Cuál? \\
\hline
\end{tabular}

56. De los siguientes espacios de participación ciudadana ¿en cuáles ha

\begin{tabular}{|l|l|}
\hline 1. (JAC) Juntas de Acción Comunal & 1 \\
\hline 2. (JAL) Juntas Administradoras Locales & 2 \\
\hline 3. Comités de control social & 3 \\
\hline 4. Comités de participación comunitaria en salud & 4 \\
\hline 5. Audiencias públicas & 5 \\
\hline 6. Veedurías ciudadanas & 6 \\
\hline 7. Ninguno de los anteriores & 7 \\
\hline
\end{tabular}

55. ¿Con cuáles de las siguientes ideologías políticas se identifica?

\begin{tabular}{|l|l|}
\hline 1. Derecha & 1 \\
\hline 2. Centro derecha & 2 \\
\hline 3. Centro & 3 \\
\hline 4. Centro izquierda & 4 \\
\hline 5. Izquierda & 5 \\
\hline 6. Ninguna & 6 \\
\hline 7. Ns/Nr & 7 \\
\hline
\end{tabular}

57. ¿Alguna vez ha realizado alguna de las siguientes acciones a favor de la conservación del medio ambiente?

\begin{tabular}{|l|l|}
\hline 1. Separación adecuada de basuras & 1 \\
\hline 2. Reciclaje & 2 \\
\hline 3. Reutilización de lementos inorgánicos & 3 \\
\hline $\begin{array}{l}\text { 4. Participa en alguna organización } \\
\text { ecologista }\end{array}$ & 4 \\
\hline $\begin{array}{l}\text { 5. Información y divulgación entre sus } \\
\text { pacientes sobre el reciclaje y cuidado del } \\
\text { medio ambiente }\end{array}$ & 5 \\
\hline $\begin{array}{l}\text { 6. Participa de jornadas de promoción e } \\
\text { información del cuidado del medio }\end{array}$ & 6 \\
\hline 7. Ninguna de las anteriores & 7 \\
\hline
\end{tabular}

\section{SATISFACCIÓN Y EXPECTATIVAS LABORALES}

58. ¿Cuál es su grado de satisfacción o insatisfacción con...

\begin{tabular}{|l|c|c|c|c|c|}
\hline & $\begin{array}{c}\text { Muy } \\
\text { satisfecho }\end{array}$ & Satisfecho & $\begin{array}{c}\text { Ni satisfecho } \\
\text { ni insatisfecho }\end{array}$ & Insatisfecho & $\begin{array}{c}\text { Muy } \\
\text { insatisfecho }\end{array}$ \\
\hline 1. Sus condiciones de vida & 5 & 4 & 3 & 2 & 1 \\
\hline 2. Las actividades que realiza en el tiempo libre & 5 & 4 & 3 & 2 & 1 \\
\hline 3. Los ingresos derivados de su ejercicio profesional & 5 & 4 & 3 & 2 & 1 \\
\hline 4. La calidad del sistema de salud vigente & 5 & 4 & 3 & 2 & 1 \\
\hline 5. Sus condiciones laborales actuales & 5 & 4 & 3 & 2 & 1 \\
\hline
\end{tabular}

59. ¿Cómo caliica la caldiad del servicio médico en Colombia bajo el sistema de la Ley 100 de 1993?

\begin{tabular}{|l|c|}
\hline 1. Muy buena & 5 \\
\hline 2. Buena & 4 \\
\hline 3. Regular & 3 \\
\hline 2. Mala & 2 \\
\hline 5. Muy mala & 1 \\
\hline
\end{tabular}

60. En su opinión la Ley 100 de 1993 y sus consecutivas reformas han implicado...

\begin{tabular}{|l|l|}
\hline $\begin{array}{l}\text { 1. Un mejoramiento de las condiciones } \\
\text { laborales y salariales de los médicos }\end{array}$ & 1 \\
\hline $\begin{array}{l}\text { 2. Un desmejoramiento de las condiciones } \\
\text { laborales y salariales de los }\end{array}$ & 2 \\
\hline $\begin{array}{l}\text { 3. No ha implicado un cambio significativo } \\
\text { para las condicones laborales y salariales } \\
\text { de los médicos generales }\end{array}$ & 3 \\
\hline
\end{tabular}


61. ¿Actualmente dispone de horas libres para

$$
\begin{array}{l|l|}
\text { 1. Sí } & 1 \\
\text { 2. No } & 2 \\
\hline
\end{array}
$$

Cuántas horas

63. ¿Le gustaría estudiar una especialización?
1. Sí$$
1
$$
2. No
¿Cuál

65. ¿Conoce a algún médico general que se encuentre desempleado en el último año?
1. Sí

$$
\begin{array}{|l|}
\hline 1 \\
\hline 2 \\
\hline
\end{array}
$$
2. No

Cuántos

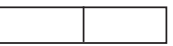

62. Si tuviese la oportunidad le gustaría...

1. Seguir trabajando en Pasto

2. Trabajar en otros municipios del depto.

3. Trabajar en otros municipios de Colombia 3

4. Trabajar en otro país

64. Sus expectativas para los próximos 5 años son:

1. Seguir trabajando como lo ha venido haciendo

2. Montar un negocio de saludo de otra área

3. Buscar en empleo en otra ciudad para mejorar su situación económica

4. Otra. ¿cuál?

\begin{tabular}{|l|}
\hline 1 \\
\hline 2 \\
\hline 3 \\
\hline 4 \\
\hline
\end{tabular}

66. ¿Usted ha estado desempleado?
1. Sí

\begin{tabular}{|l|}
\hline 1 \\
\hline 2 \\
\hline
\end{tabular}

Cuánto tiempo?

Observaciones:

\section{CONTROL DE LA ENCUESTA (Para el encuestador) \\ Encuestador Nombre}

Nombre

\section{CONTROL DE LA ENCUESTA}

Fecha:

Hora de inicio:

\begin{tabular}{|c|c|c|c|}
\hline \multirow[t]{3}{*}{ Realización de la encuesta } & Institución & \multirow{3}{*}{$\begin{array}{l}\text { Residencia } \\
\text { Otro }\end{array}$} & No. visita \\
\hline & Consultario & & 1 \\
\hline & & & 2 \\
\hline & & & 3 \\
\hline
\end{tabular}

Hora de finalización:

Observaciones:

Fuente: elaboración propia con información de Poveda (2013), DANE (2012) y CIS (2002) 